\title{
Self-priming on the plant viral RNAs during reverse transcription-PCR
}

\author{
C. ZHANG ${ }^{1}$, H. N. WU ${ }^{1}$, Y. Q. ZHANG ${ }^{1}$, J. G. SHEN², W. M. LI $^{1 *}$
}

${ }^{1}$ Biotechnology Research Institute, Chinese Academy of Agricultural Sciences, Beijing, 100081, P. R. China; ${ }^{2}$ Inspection \& Quarantine Technology Center, Fujian Entry-Exit Inspection and Quarantine Bureau, Fuzhou, 350001, P. R. China

Received September 29, 2014; accepted February 12, 2015

\begin{abstract}
Summary. - The occurrence of the primer-independent cDNA synthesis during RT-PCR analysis of human and animal RNA viruses has been well documented. Conversely, there is scant knowledge about this event in plant RNA viruses. Here we show that the primer-independent cDNA synthesis occurs in all eight different plant RNA viruses tested in this study, suggesting a common phenomenon for RT-PCR analysis of plant RNA viruses. Additional experiments indicate that the event is likely contributed to by RNA self-priming, and can be effectively reduced or eliminated through increasing temperature of the RT reaction.
\end{abstract}

Keywords: RT-PCR; primer-independent cDNA synthesis; self-priming; plant RNA virus; RT temperature

RT-PCR is one of the most common methods of molecular biology used to detect and quantify RNA expression levels in both cells and small quantities of tissues. Within this process, RT is the first and fundamental step, in which the RNA template is converted into its cDNA by reverse transcriptase in the presence of exogenous oligonucleotide referred to as primer, providing template DNA for subsequent PCR amplification. The primer-dependent mechanism for RT reaction has been generally accepted over the years. However, during RT-PCR analysis of human and animal RNA viruses, bacterial operons, as well as eukaryotic cellular RNAs, it has been observed that cDNA could be synthesized by reverse transcriptase without the addition of exogenous oligonucleotide (Gunji et al., 1994; Lanford et al., 1995; Lerat et al., 1996; Schoenike et al., 1999; Guacucano et al., 2000; Peyrefitte et al., 2003; Haddad et al., 2007; Tuiskunen et al.,

*Corresponding author. E-mail: liweimin01@caas.cn; phone: +8610-82106117. C. Zhang. and H.N. Wu contributed equally to this work.

Abbreviations: CGMMV = cucumber green mottle mosaic virus; $\mathrm{CMV}$ = cucumber mosaic virus; gRNA = genomic RNA; ORSV = odontoglossum ring-spot virus; $\mathrm{PVX}$ = potato virus $\mathrm{X}$; $\mathrm{TCV}=$ turnip crinkle virus; TMV U1 = tobacco mosaic virus $\mathrm{U} 1$ strain; $\mathrm{TNV}=$ tobacco necrosis virus; $\mathrm{TRV}=$ tobacco rattle virus
2010, Moison et al., 2011). This completely contradicts the well-accepted mechanism of cDNA synthesis, indicating that RT occurs in a primer-independent manner.

Thus far, several explanations have been proposed to clarify the origin of the primer-independent event. It was postulated that Taq polymerase probably possesses the background reverse transcriptase activity that might be active in the PCR step once forward and reverse primers are present, thus leading to the confusing result (Martel et al., 2002). However, many lines of evidence supported the possibility that this kind of cDNA synthesis is most likely primed by cellular small nucleic acids (DNA, microRNA, tRNA, etc.) associated with the commercial reverse transcriptase as well as template RNA, or by the thermosTable hairpin structure at the 3'-end of the template RNA, the so called self-priming (Agranovsky, 1992; Gunji et al., 1994; Lerat et al., 1996; Timofeeva and Skrypina, 2001; Piche and Schernthaner, 2003; Haddad et al., 2007; Tuiskunen et al., 2010; Moison et al., 2011). Regardless, since the primer-independent RT usually contributes to non-specific cDNA synthesis that may interfere with the PCR specificity, thus resulting in misinterpretation of the final experimental data, much effort has been devoted to overcoming this unexpected event (Lerat $e t$ al., 1996; Peyrefitte et al., 2003; Haddad et al., 2007; Moison et al., 2011). Of the developed strategies, tagged RT primer 
as well as high temperature reverse transcription has been proved to be effective in achieving strand-specific amplification (Peyrefitte et al., 2003; Haddad et al., 2007; Moison et al., 2011). It is worth to note that the two methods rely on different mechanisms. The former allows making the falsely primed cDNA undetecTable rather than to avoid it, whereas the latter maintains the RT reaction at high temperature to minimize the non-specific cDNA synthesis.

Plant RNA viruses are a group of major agricultural pathogens that cause a number of economically important plant diseases worldwide (Reddy et al., 2009; Scholthof et al., 2011). To mitigate or prevent a viral disease from occurring, the conventional RT-PCR has become the one routine technique to detect the plant RNA viruses due to its sensitivity and ready availability (Thomson and Dietzgen, 1995). So far, however, little attention was paid to the primer-independent cDNA synthesis during plant RNA virus identification or diagnosis, probably because this event has no or little effect on the final result of common RT-PCR used for these purposes. Tobacco mosaic virus (TMV) U1 is one of the most well-known plant RNA viruses that belongs to the genus Tobamovirus (Creager et al., 1999; Scholthof et al., 2011). Recently, we showed that this positive-strand RNA virus, which is known to terminate with 3' tRNA-like structures, possesses a small proportion of genomic RNA (gRNA) bearing polyadenylated tails (Li et al., 2014). Regarding the nature of the poly(A) tails, we initially performed RT-PCR with oligo $(\mathrm{dT})_{18}$ as RT primer to characterize these special TMV gRNA molecules. However, the same PCR product could also be produced in the negative control experiment, wherein the RT reaction was carried out without addition of oligo $(\mathrm{dT})_{18}$ as well as any other exogenous primer (data not shown). This unexpected data implied that the primer-independent cDNA synthesis might occurred during RT-PCR detection of TMV gRNA but await further elucidation.

To address this concern, in the present study we performed RT-PCR on TMV gRNA as described below. Total RNA was first extracted from the TMV U1-infected Nicotiana benthamiana leaves with Trizol (Invitrogen) according to the manufacturer's instructions and used as a template to perform RT with M-MLV Reverse Transcriptase, RNase $\mathrm{H}$ Minus (Promega) as follows: $1 \mu \mathrm{g}$ of total RNA was denatured at $65^{\circ} \mathrm{C}$ for $5 \mathrm{~min}$ in the presence of $20 \mathrm{pmol} \mathrm{TMV}$ 6395-76 (Table 1), a gene-specific primer corresponding to the extreme 3 ' end of TMV gRNA, or without any primer addition, then was chilled on ice for $2 \mathrm{~min}$; the RT reactions in a total volume of $25 \mu \mathrm{l}$ containing $0.5 \mathrm{mmol} / \mathrm{l}$ of dNTPs, $200 \mathrm{U}$ of M-MLV, $5 \mu \mathrm{l}$ reaction buffer $(5 \times), 10 \mathrm{U}$ RNase inhibitor (Promega) were subsequently incubated at $42^{\circ} \mathrm{C}$ for 1 $\mathrm{hr}$, followed by a heating step at $95^{\circ} \mathrm{C}$ for $10 \mathrm{~min}$ to inactivate RT enzyme. The amplification of the cDNA product as a template was carried out immediately using LA Taq (Takara) in a reaction containing $1 \mu \mathrm{l}$ cDNA in a $20 \mu \mathrm{l}$ reaction mix containing 10 pmol of each of the primers TMV-6023-44 and

Table 1. Oligonucleotides used in this study

\begin{tabular}{|c|c|c|c|c|}
\hline Oligo name & Organism & Application & Direction & Primer sequence $\left(5^{\prime}-3^{\prime}\right)$ \\
\hline TMV-6023-44 & TMV & PCR & Forward & GACTGCCGAAACGTTAGATGCT \\
\hline TMV-6395-76 & TMV & RT/PCR & Reverse & TGGGCCCCTACCGGGGGTAA \\
\hline CGMMV-5763-83 & CGMMV & PCR & Forward & ATGGCTTACAATCCGATCACA \\
\hline CGMMV-6424-05 & CGMMV & RT/PCR & Reverse & TGGGCCCCTACCCGGGGAAA \\
\hline ORSV-6065-85 & ORSV & PCR & Forward & CAACTCGTAGAGTTGATGATG \\
\hline ORSV-6618-597 & ORSV & RT/PCR & Reverse & TGGGCCTCTACCCGAGGTAA \\
\hline CMV1-2698-717 & CMV(RNA1) & PCR & Forward & CACGAAATGGGTTTCTCAAT \\
\hline CMV1-3357-38 & CMV(RNA1) & RT-PCR & Reverse & TGGTCTCCTTTTAGAGACCC \\
\hline TRV1-6177-97 & TRV(RNA1) & PCR & Forward & GGTCATGCTAACAAATTGCGA \\
\hline TRV1-6791-72 & TRV(RNA1) & $\mathrm{RT} / \mathrm{PCR}$ & Reverse & GGGCGTAATAACGCTTACGT \\
\hline TCV-3564-84 & TCV & PCR & Forward & GAGCACGATTGTCATTTTCTC \\
\hline TCV-4050-28 & TCV & $\mathrm{RT} / \mathrm{PCR}$ & Reverse & GGGCAGGCCCCCCCCCCGCGCGA \\
\hline TNV-3021-41 & TNV & PCR & Forward & GTGAGCTCATCTACATACCTA \\
\hline TNV-3682-63 & TNV & RT/PCR & Reverse & GGGGTGGGGCAAAAGCCCCT \\
\hline PVX5866-85 & PVX & PCR & Forward & ACAGACACTATGGCACAGGC \\
\hline PVX6435-13 & PVX & RT/PCR & Reverse & ATTTTATATTATTCATACAATCA \\
\hline
\end{tabular}

aThe oligonucleotides for viral RNAs detection were designed according to reference genomes of TMV (\#NC_001367), CGMMV(\#D12505), ORSV (\#X82130), CMV RNA1 (\#D00356), TRV RNA1 (\#AF166084), TCV (\#M22445), TNV (\#AY546104) and PVX (\#EF423572). 


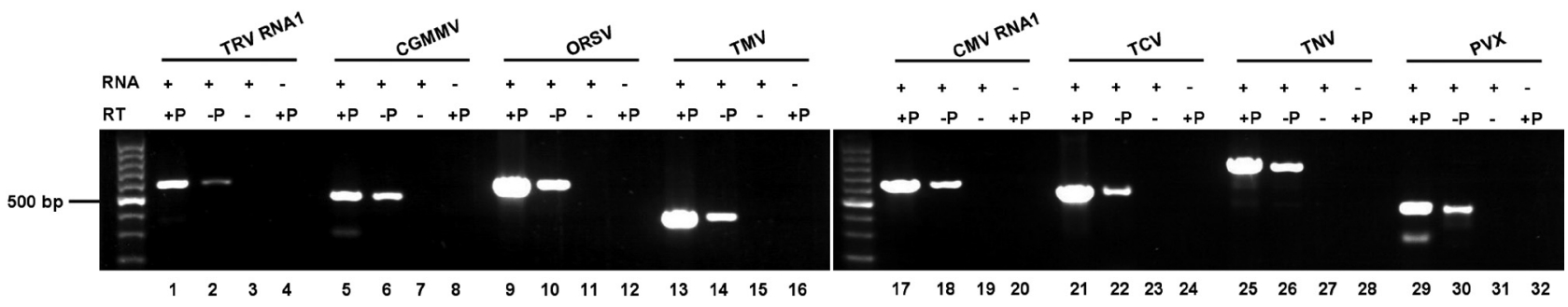

Fig. 1

Endogenous priming occurs during reverse transcription of the viral RNAs from eight different plant RNA viruses

One microgram of total RNA extracted from the virus-infected leaves of $N$. benthamiana by using Trizol was converted into cDNA in the presence or absence of specific RT primer (RT, +/-P). As a control, cDNA synthesis was carried out without addition of RT enzyme (RT -) or template RNA (RNA -). Following the RT step, the standard PCR (30 cycles) was performed and the resulting amplification products along with the 100 bp ladder were electrophoresed on a $1.2 \%$ agarose gel.

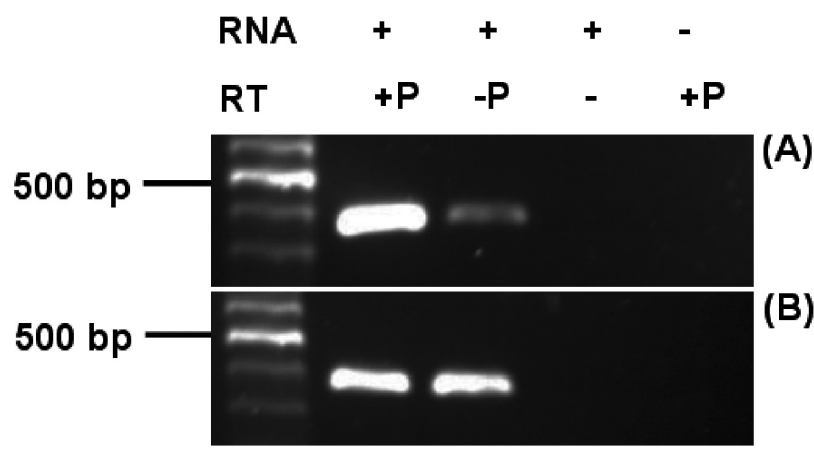

Fig. 2

Self-priming occurs during reverse transcription of the column purified RNA (panel A) as well as in vitro-transcribed RNA (panel B) cDNA synthesis was performed on $1 \mu \mathrm{g}$ of mini column purified total RNA from the virus-infected leaves of $N$. benthamiana or $100 \mathrm{ng}$ in vitro TMV RNA with or without primer (RT, +/-P). Control experiments were carried out with no RT enzyme addition (RT -) or in the absence of template RNA (RNA -). After the RT step, the standard PCR (30 cycles) was performed and the resulting amplification products along with the $100 \mathrm{bp}$ ladder were electrophoresed on a $1.2 \%$ agarose gel.
TMV-6395-76 (Table 1) and the following PCR program: 3 min at $94^{\circ} \mathrm{C}$, followed by $30 \mathrm{cycles}$ of $94^{\circ} \mathrm{C}$ for $30 \mathrm{sec}, 54^{\circ} \mathrm{C}$ for $30 \mathrm{sec}, 72^{\circ} \mathrm{C}$ for $30 \mathrm{sec}$, and then $72^{\circ} \mathrm{C}$ for $10 \mathrm{~min}$. The resulting amplicons were electrophoresed on a $1.2 \%$ agarose gel stained with ethidium bromide and visualized under UV light. As expected, cDNA synthesis upon the use of TMV6395-76 as an RT primer allowed the identification of a PCR product corresponding to nts 6023-6395 of TMV gRNA (Fig. 1, lane 13). Interestingly, cDNA synthesis in the absence of the RT primer generated a same size PCR product (Fig. 1, lane 14), and DNA sequencing revealed that the product indeed corresponded to the $3^{\prime}$ termini of TMV gRNA. To exclude the possible DNA contamination or RT activity of Taq polymerase, we conducted two additional control experiments, in which RT reaction was performed in the absence of RT enzyme or template RNA. As expected, no visible PCR product was detected (Fig. 1, lanes 15 and 16). Using the same strategy, identical results were obtained after RTPCR analysis of seven other plant RNA viruses (Fig. 1, lanes 1-12 and 17-32), including two additional tobamoviruses,

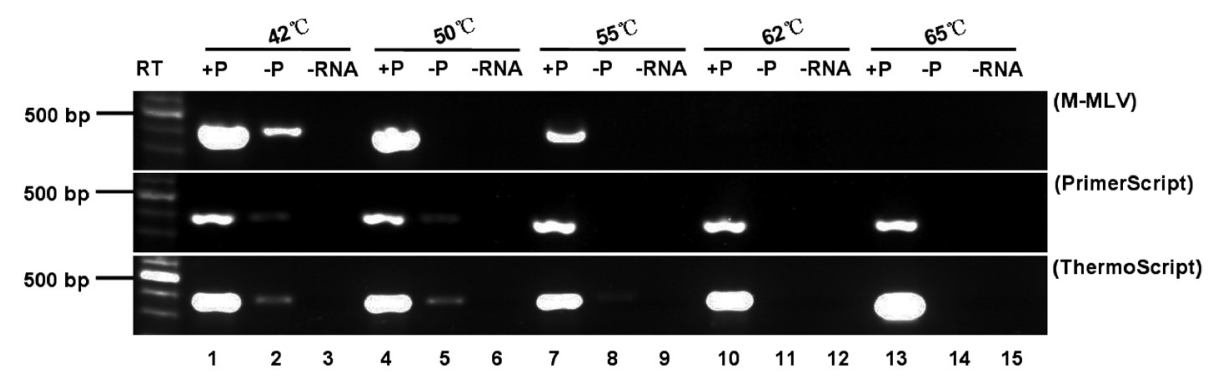

Fig. 3

The effect of the temperature on reverse transcriptase-mediated cDNA synthesis

Three different commercial reverse transcriptases, M-MLV (Promega), PrimeScript (Takara) and ThermoScript (Invitrogen) were included. Using $1 \mu \mathrm{g}$ of total RNA prepared from the TMV-infected $N$. benthamiana leaves as template, RT reactions were individually preformed at $42^{\circ} \mathrm{C}, 50^{\circ} \mathrm{C}, 56^{\circ} \mathrm{C}, 62^{\circ} \mathrm{C}$, and $65^{\circ} \mathrm{C}$ with or without specific RT primer (RT, +/-P). As a control, cDNA synthesis was carried out in the absence of the template RNA (-RNA). Following the RT step, the standard PCR (30 cycles) was performed and the resulting amplification products were electrophoresed on a $1.2 \%$ agarose gel along with the $100 \mathrm{bp}$ ladder. 


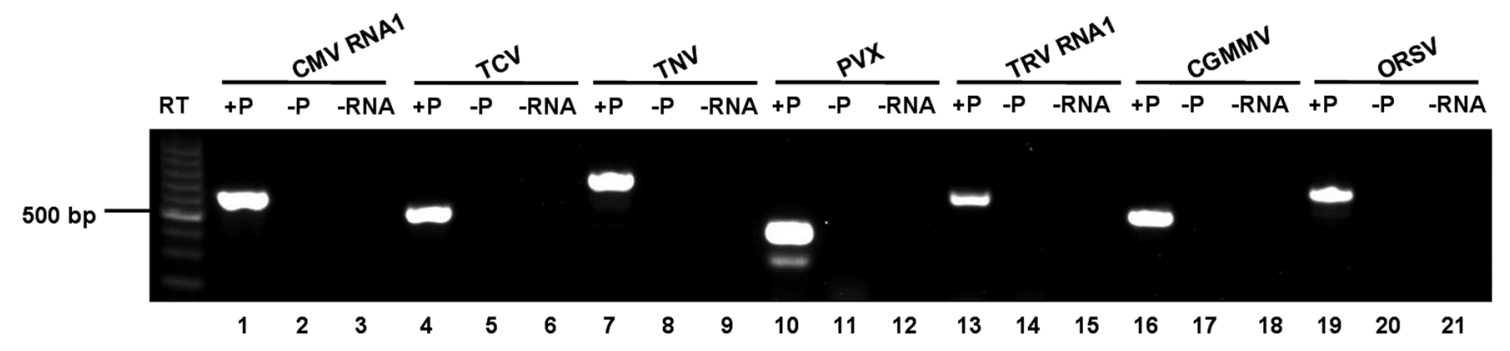

Fig. 4

Effective inhibition of RNA self-priming in a broad range of plant viral RNAs by using ThermoScript reverse transcriptase to reverse-transcribe RNA at high temperature

One microgram of total RNA extracted from the virus-infected $N$. benthamiana leaves was used as the template, and RT reactions were preformed at 62 ${ }^{\circ} \mathrm{C}$ with or without specific RT primer (+/-P). As a control, cDNA synthesis was carried out in the absence of the template RNA (-RNA). Following the RT step, the standard PCR (30 cycles) was performed and the resulting amplification products along with the 100 bp ladder were electrophoresed on a $1.2 \%$ agarose gel.

odontoglossum ring-spot virus (ORSV) and cucumber green mottle mosaic virus (CGMMV), as well as cucumber mosaic virus (CMV; the genus Cucumovirus), tobacco rattle virus (TRV; the genus Tobravirus), turnip crinkle virus (TCV; the genus Carmovirus), tobacco necrosis virus (TNV; the genus Necrovirus) and potato virus X (PVX; the genus Potexvirus). The primers used are listed in Table 1. Taken together, these data conclusively demonstrate that the primer-independent cDNA synthesis is a basic phenomenon in RT-PCR detection of many plant RNA viruses, and probably occurs with endogenous priming at the 3 ' termini of viral RNA.

As far as is known, the endogenous priming was likely caused by the intrinsic property of the template RNA or cellular small nucleic acids associated with reverse transcriptase and template RNA preparations. Regarding the fact that M-MLV reverse transcriptase used in the current study contains only few small RNA contaminations (Agranovsky, 1992; Moison et al., 2011), the possibility that reverse transcriptase serves as a source of non-specific cDNA synthesis could be excluded herein. Accordingly, the following experiments were performed to clarify whether cellular small nucleic acids within RNA preparations contributed to the primer-independent cDNA synthesis. Taking the advantage of RNeasy Plant Mini Kit (QIAGEN) in removal of small nucleic acids, we first prepared the template RNA from the TMV-infected $N$. benthamiana leaves by utilizing this kit instead of Trizol used above. As a result, this strategy failed to avoid the primer-independent cDNA synthesis (Fig. 2a). Additionally, to further rule out the influence of trace amounts of cellular nucleic acids, we prepared in vitro RNA transcripts of TMV U1 from linearized plasmids as described (Dawson et al., 1986). PCR amplification was first performed by using 100 ng of the DNaseI-treated RNA transcripts as a template without prior reverse transcription, ensuring the complete removal of the DNA template (data not shown). However, the primer-independent event remained in the RT-PCR analysis of the pure RNA transcripts (Fig. 2b). Taking all the observations into account, we determined that small nucleic acids are poorly associated with the endogenous priming, whereas the RNA self-priming should account for the primer-independent cDNA synthesis.

Previous reports showed that the increase of RT reaction temperature is an effective approach to attenuate or eliminate the RNA self-priming in cDNA synthesis (Haddad et al., 2007; Moison et al., 2011). We therefore adopted this strategy to overcome the RNA self-priming that occurs in RT-PCR detection of plant RNA viruses. Meanwhile, given that increasing the temperature would inevitably affect the efficiency of RT, in addition of M-MLV used above, PrimeScript (Takara) and ThermoScript (Invitrogen), two additional commercial reverse transcriptases with higher thermal stability (the recommended reaction temperature for $\mathrm{M}-\mathrm{MLV}$ is of $42^{\circ} \mathrm{C}$, whereas $50^{\circ} \mathrm{C}$ for PrimeScript and $62^{\circ} \mathrm{C}$ for ThermoScript) were included herein to systematically compare their properties in RT reaction. Using total RNA $(1 \mu \mathrm{g})$ of the TMV-infected Nicotiana benthamiana leaves as a template, $\mathrm{RT}$ reactions were preformed at progressively increased temperature of $42^{\circ} \mathrm{C}, 50^{\circ} \mathrm{C}, 56^{\circ} \mathrm{C}, 62^{\circ} \mathrm{C}$, and 65 ${ }^{\circ} \mathrm{C}$, respectively. The subsequent PCR amplification indicated that all reverse transcriptases compromised to the RNA selfpriming in CDNA synthesis at lower reaction temperatures, which, however, could be successfully eliminated or reduced to below detection level by increasing RT reaction temperature (Fig. 3). Notably, with increasing RT temperature, the activity of M-MLV was significantly attenuated, and no PCR product was amplified at all once the $\mathrm{RT}$ temperature reached $62^{\circ} \mathrm{C}$ (Fig. 3, lane 10). In contrast, both PrimeScript and ThermoScript remained active even at $65^{\circ} \mathrm{C}$ (Fig. 3, lane 13). Particularly, ThermoScript, as a thermosTable enzyme, seemed to become more efficient when the RT temperature was increased from $42^{\circ} \mathrm{C}$ to $65^{\circ} \mathrm{C}$. Hence, ThermoScript was applied in RT-PCR detection of the other seven plant 
RNA viruses mentioned above. When cDNA synthesis was performed at $62^{\circ} \mathrm{C}$ but in the absence of the RT primer, the subsequent PCR amplification identified no visible product (Fig. 4, lanes 2, 5, 8, 11, 14, 17, and 20), indicating that increasing RT temperature is useful in preventing self-priming on a broad range of plant viral RNAs.

In conclusion, we show here that the primer-independent cDNA synthesis occurs widely during RT-PCR detection of plant RNA viruses, and is most likely caused by RNA selfpriming. In view of the identification or diagnosis of plant RNA viruses, RNA self-priming is unlikely to affect the final result of the assay, and could even be beneficial, since it can amplify the signal and thus increase the sensitivity of the assay. However, once the aim of RT-PCR is to test the specific strand of the sense-antisense viral RNA pairs or some specific viral RNA molecules such as the TMV RNA with poly(A) tails, this event may give inaccurate or false positive results, leading to misinterpretation. While increasing RT temperature could eliminate or reduce RNA self-priming, setting up the appropriate negative controls remains essential to ensure the specificity of the RT-PCR reaction.

Acknowledgements. We thank Dr. William Dawson (University of Florida, USA) for providing the cDNA clone of TMV U1. This work was supported by the National Natural Science Foundation of China (31170140), the Special Fund for Agro-scientific Research in the Public Interest (201303028) and Fujian Natural Science Funds for Distinguished Young Scholar (2014J06008).

\section{References}

Agranovsky AA (1992): Exogenous primer-independent cDNA synthesis with commercial reverse transcriptase preparations on plant virus RNA templates. Anal. Biochem. 203, 163-165. http://dx.doi.org/10.1016/0003-2697(92)90058-F

Bessaud M, Autret A, Jegouic S, Balanant J, Joffret ML, Delpeyroux F (2008): Development of a Taqman RT-PCR assay for the detection and quantification of negatively stranded RNA of human enteroviruses: evidence for false-priming and improvement by tagged RT-PCR. J. Virol. Methods 153, 182-189. http://dx.doi.org/10.1016/j. jviromet.2008.07.010

Creager AN, Scholthof KB, Citovsky V, Scholthof HB (1999): Tobacco mosaic virus. Pioneering research for a century. Plant Cell 11, 301-308. http://dx.doi.org/10.1105/tpc.11.3.301

Dawson WO, Beck DL, Knorr DA, Grantham GL (1986): cDNA cloning of the complete genome of tobacco mosaic virus and production of infectious transcripts. Proc. Natl. Acad. Sci. USA. 83, 1832-1836. http://dx.doi.org/10.1073/ pnas.83.6.1832

Guacucano M, Martínez GL, Holmes DS, Jedlicki E (2000): An RTPCR artifact in the characterization of bacterial operons. Electron. J. Biotechnol. 3, 213-216.
Gunji T, Kato N, Hijikata M, Hayashi K, Saitoh S, Shimotohno K (1994): Specific detection of positive and negative stranded hepatitis C viral RNA using chemical RNA modification. Arch. Virol. 134, 293-302. http://dx.doi. org/10.1007/BF01310568

Haddad F, Qin AX, Giger JM, Guo H, Baldwin KM (2007): Potential pitfalls in the accuracy of analysis of natural sense-antisense RNA pairs by reverse transcription-PCR. BMC Biotechnol. 7, 21. http://dx.doi.org/10.1186/14726750-7-21

Lanford RE, Chavez D, Chisari FV, Sureau C (1995): Lack of detection of negative-strand hepatitis $\mathrm{C}$ virus RNA in peripheral blood mononuclear cells and other extrahepatic tissues by the highly strand-specific rTth reverse transcriptase PCR. J. Virol. 69, 8079-8083.

Lerat H, Berby F, Trabaud MA, Vidalin O, Major M, Trépo C, Inchauspé $G$ (1996): Specific detection of hepatitis $C$ virus minus strand RNA in hematopoietic cells. J. Clin. Invest. 97, 845-851. http://dx.doi.org/10.1172/JCI118485

Li WM, Zhang Y, Zhang C, Pei X, Wang Z, Jia S (2014): Presence of poly(A) and poly(A)-rich tails in a positive-strand RNA virus known to lack 3' poly(A) tails. Virology 454-455, 1-10. http://dx.doi.org/10.1016/j.virol.2014.02.002

Martel F, Gründemann D, Schömig E (2002): A simple method for elimination of false positive results in RT-PCR. J. Biochem. Mol. Biol. 35, 248-250. http://dx.doi.org/10.5483/ BMBRep.2002.35.2.248

Moison C, Arimondo PB, Guieysse-Peugeot AL (2011): Commercial reverse transcriptase as source of false-positive strand-specific RNA detection in human cells. Biochimie. 93, 1731-1737. http://dx.doi.org/10.1016/j. biochi.2011.06.005

Peyrefitte CN, Pastorino B, Bessaud M, Tolou HJ, Couissinier-Paris $P$ (2003): Evidence for in vitro falsely-primed cDNAs that prevent specific detection of virus negative strand RNAs in dengue-infected cells: improvement by tagged RT-PCR. J. Virol Methods 113, 19-28. http://dx.doi.org/10.1016/ S0166-0934(03)00218-0

Piche C, Schernthaner JP (2003): Background priming during reverse transcription by oligo(dT) carried over from mRNA isolation. Biotechniques 34, 720-722, 724.

Reddy DV, Sudarshana MR, Fuchs M, Rao NC, Thottappilly G (2009): Genetically engineered virus-resistant plants in developing countries: current status and future prospects. Adv. Virus Res. 75, 185-220. http://dx.doi.org/10.1016/ S0065-3527(09)07506-X

Schoenike B, Franta AK, Fleming JO (1999): Quantitative sensespecific determination of murine corona virus RNA by reverse transcription polymerase chain reaction. J. Virol. Methods 78, 35-49. http://dx.doi.org/10.1016/S01660934(98)00167-0

Scholthof, KB, Adkins S, Czosnek H, Palukaitis P, Jacquot E, Hohn T, Hohn B, Saunders K, Candresse T, Ahlquist P, Hemenway C, Foster GD (2011): Top 10 plant viruses in molecular plant pathology. Mol. Plant Pathol. 12, 938-954. http:// dx.doi.org/10.1111/j.1364-3703.2011.00752.x

Thomson D, Dietzgen RG (1995): Detection of DNA and RNA plant viruses by PCR and RT-PCR using a rapid virus 
release protocol without tissue homogenization. J. Virol. Methods 54, 85-95. http://dx.doi.org/10.1016/01660934(95)00022-M

Timofeeva AV, Skrypina NA (2001): Background activity of reverse transcriptases. Biotechniques 30, 22-24, 26, 28.

Tuiskunen A, Leparc-Goffart I, Boubis L, Monteil V, Klingström J, Tolou HJ, Lundkvist A, Plumet S (2010): Self-priming of reverse transcriptase impairs strand-specific detection of dengue virus RNA. J. Gen. Virol. 91, 1019-1027. http:// dx.doi.org/10.1099/vir.0.016667-0 